\title{
O BULLYING NA EDUCAÇÃO FÍSICA ESCOLAR E SUA DIFERENÇA ENTRE MENINOS E MENINAS
}

\author{
Riana Duarte Linhares \\ Fundação Universitária da Itaperuna, Itaperuna, Rio de Janeiro, Brasil \\ João Paulo Oliveira Faria \\ Fundação Universitária da Itaperuna, Itaperuna, Rio de Janeiro, Brasil \\ Raquel Guimarães Lins \\ Fundação Universitária da Itaperuna, Itaperuna, Rio de Janeiro, Brasil
}

\begin{abstract}
Resumo
O objetivo foi analisar a relação do gênero com os tipos de bullying mais frequentes nas aulas de Educação Física Escolar do $6^{\circ}$ ano do Ensino Fundamental. Foram selecionadas as quatro maiores escolas da rede municipal de Itaperuna e aplicado um questionário sobre bullying em 141 estudantes. Verificou-se que as diferenças entre os sexos não foram significativas, sendo mais encontrado nas meninas vítimas de bullying o tipo verbal e o psicológico/moral e nos meninos vítimas o verbal e psicológico/moral. O bullying mais comum entre os grupos foi o psicológico/moral, não apresentando diferença entre meninos e meninas, nem entre vítimas e agressores. Não houve mudança no comportamento feminino; nos meninos houve mudança na forma de agressão ou reação.
\end{abstract}

Palavras-chave: Bullying. Identidade de Gênero. Educação Física e Treinamento.

\section{Introdução}

$\mathrm{B}$ ullying é um termo utilizado para nomear todo tipo de agressividade intencional e perversa ligada às relações interpessoais (SILVA, 2010). O bullying dessa forma pode acontecer no ambiente de trabalho, em casa, na rua ou em qualquer lugar onde exista o convívio social. Nesta pesquisa, o bullying aparecerá inserido no ambiente escolar, mais especificamente durante as aulas de Educação Física.

Maus-tratos e bullying não devem ser confundidos: para esclarecimento desta diferença, basta observar o tempo de duração de ambos. Na prática de maus-tratos, as agressões duram no máximo uma semana; já na prática de bullying; as agressões acontecem dentro de um período mais longo, sendo no mínimo três vezes no mesmo ano. Assim, pode- se considerar que bullying está relacionado ao tempo de duração e frequência de maus-tratos. Por isso, recebe o nome de Sín- 
drome de Maus-Tratos Repetitivos (SMAR), que é como ela menciona um ciclo vicioso, pois a vítima reproduz as agressões sofridas em outros indivíduos (FANTE, 2005).

A justificativa de sua discussão nos dias atuais se dá pelo fato do bullying ser um tipo de violência que, como qualquer outra, traz para os envolvidos patologias como depressão, transtorno compulsivo obsessivo e do pânico, sintomas psicossomáticos, anorexia e bulimia dentre outras, podendo chegar aos casos mais graves, porém menos frequentes como a esquizofrenia, o suicídio e o homicídio. Se os casos de bullying não forem reconhecidos o quanto antes e as devidas estratégias não forem adotadas, o desenvolvimento do estudante será prejudicado não somente na dimensão cognitiva, mas também nas sociais e afetivas (SILVA, 2010).

Apesar de sua existência ser demasiadamente antiga, somente em meados dos anos 90 começaram as pesquisas dentro do tema. Hoje, muitos pesquisadores buscam, através de estudos, conscientizar os profissionais da área da educação e psicologia, pais, equipe de apoio escolar e todos os alunos sobre esse mal que aflige a sociedade e que já é hoje considerado um problema de saúde pública. As divulgações exacerbadas da mídia e das muitas pesquisas que abordam o tema estimulam os alunos, vítimas e expectadores, a não se esconderem atrás do silêncio imposto pelo agressor, mas a denunciarem as agressões sofridas.

A importância de estudar o bullying nas aulas de Educação Física se dá por esta ser um local onde a relação interpessoal acontece de forma mais intensa que nas outras disciplinas. A quadra esportiva é um dos locais na escola onde é possível encontrar situações desse tipo, principalmente no segundo segmento do Ensino Fundamental, no qual o bullying está mais visível (FANTE; PEDRA, 2008).

A ligação histórica da disciplina de Educação Física à área da saúde fez com que a divisão dos gêneros, masculino e feminino, acontecessem durante as aulas. A adaptação das atividades propostas pelo educador/educadora somente fortalece a ideia de que as meninas são menos habilidosas que os meninos, permitindo que este ajuste das regras aconteça para que elas, -menos habilidosas, possam participar das atividades. É indispensável para a formação do aluno que as aulas de Educação Física tenham a preocupação de trabalhar a cultura corporal em sua totalidade, não se limitando à simples reprodução do movimento (LOURO, 2003). 
Este trabalho busca analisar a relação do gênero com os tipos de bullying mais frequentes nas aulas de Educação Física do $6^{\circ}$ ano do Ensino Fundamental das escolas da Rede Municipal de Itaperuna. Para que assim, os professores da área possam, de forma mais crítica, ficar alerta para identificar este fenômeno na sua instituição de trabalho, intervindo com atividades que diminuam sua frequência.

A importância desse estudo está pautada em várias áreas da saúde, educação, comunicação e política. Na psicologia, estes profissionais poderão, pelo menos dentro da realidade de Itaperuna, identificar como o gênero pode influenciar no bullying, para que assim o tratamento por ele adotado possa ser mais preciso e eficiente, uma vez que já possui uma consciência da realidade de algumas escolas. Jornalistas podem ajudar divulgando e alertando a população sobre a seriedade do tema abordado, denunciando toda indiferença diante do assunto. Esta pesquisa permitirá conhecer mais sobre o fenômeno, sendo mais uma forma de contribuir com dados sobre a violência escolar e a diferença encontrada entre meninos e meninas na Educação Física Escolar.

\section{Problema}

Estudos sobre gênero se fazem necessários para oferecer aos indivíduos uma concepção de corpo que tenha suas práticas envolvendo todos, independente do sexo, idade e classe socioeconômica, permitindo ainda que percebam a influência das questões de gênero em nosso dia-a-dia. (KNIJNIK, 2010) Neste sentido, buscou-se identificar qual a relação do gênero com o bullying na Educação Física Escolar no $6^{\circ}$ ano do ensino fundamental da Rede Municipal do município de Itaperuna.

\section{Objetivos}

O presente estudo tem como objetivo analisar a relação do gênero com os tipos de bullying mais frequentes nas aulas de Educação Física do $6^{\circ}$ ano do Ensino Fundamental das escolas da Rede Municipal de Itaperuna. Como objetivo específico, tem-se comparar as diferenças entre meninos e meninas nos tipos de bullying mais frequentes na Educação Física Escolar. 


\section{Metodologia}

A amostra da pesquisa consta de 141 (cento e quarenta e um) estudantes, do $6^{\circ}$ ano, do $2^{\circ}$ segmento do Ensino Fundamental da Rede Municipal de Itaperuna no estado do Rio de Janeiro, dentro de um total de 333 (trezentos e trinta e três) alunos matriculados nas quatro escolas participantes do estudo, de acordo com a Secretaria de Educação do Município de Itaperuna no primeiro semestre deste ano. Desses 141 indivíduos, 79 (56,8\%) eram do sexo feminino e $60(43,2 \%)$ do sexo masculino.

A pesquisa de caráter quali-quantitativo foi realizada nas quatro maiores escolas da Rede Municipal de Itaperuna com turmas do $6^{\circ}$ ano do Ensino Fundamental. A escolha intencional dessas instituições escolares aconteceu por elas apresentarem grupos de diferentes classes sociais, turmas mistas e possuírem alunos que residem tanto na zona urbana como na zona rural. Foi utilizado o questionário desenvolvido por Bandeira (2009) em sua dissertação de mestrado intitulada: "Bullying: autoestima e diferenças de gênero". Questionário fechado composto de 15 questões objetivas sobre bullying, com uma breve introdução sobre o assunto abordado. Este questionário permite a identificação de agressores, vítimas e expectadores, além de identificar o tipo de bullying e a frequência de sua ocorrência - neste presente estudo, nas aulas de Educação de Física.

Uma carta de apresentação foi entregue em duas vias, uma para escola e outra para ficar arquivada. Além disso, foi solicitada a autorização dos pais para participação dos alunos. Durante a aplicação do questionário o professor da turma e dois responsáveis pela pesquisa estiveram presentes para assegurar a significância dos resultados adquiridos.

A interpretação dos dados foi realizada por meio da estatística descritiva, média, moda e desvio padrão. A função crosstabs com teste qui quadrado foi empregada para correlacionar as variáveis analisadas. Em todos os casos, considerou-se $\mathrm{p} \leq 0,05$.

\section{Resultados}

A média de idade dos alunos participantes desta pesquisa foi de 12 anos $(41,8 \%)$, tendo dois indivíduos com 17 anos $(1,4 \%)$ e dois com 15 anos $(1,4 \%)$. 
Neste trabalho, houve um número maior de indivíduos na amostra feminina (79) quando comparado à amostra masculina (60). Assim, o sexo feminino é predominante $(56,8 \%)$ ao sexo masculino $(43,2 \%)$ nesse estudo. Dois indivíduos $(1,4 \%)$ não se identificaram como sendo pertencentes do sexo masculino e feminino.

Ao se trabalhar a variável do sexo e correlacionar com o perfil de bullying, observou-se que quando comparadas meninas e meninos (Tabela I), são mais frequentes meninas vítimas $(68,8 \%)$ e testemunhas $(68,2 \%)$ e meninos agressores $(64,7 \%)$ e vitimas/agressoras $(44,0 \%)$. Dentro do grupo feminino a maioria $(40,3 \%)$ nunca presenciou o fenômeno e das que presenciaram $19,5 \%$ se enquadraram dentro do perfil de testemunha. Dentro do grupo masculino $40,4 \%$ nunca presenciaram e dos que presenciaram agressores e vítimas/agressoras empataram em 19,3\%. Logo, têm-se mais meninas vítimas e testemunhas e mais meninos agressores e vítimas/agressoras.

\begin{tabular}{|c|c|c|c|c|c|c|c|}
\hline \multicolumn{2}{|c|}{ Sexo } & V & $A$ & VIA & $T$ & NP & Total \\
\hline \multirow[b]{2}{*}{$F$} & $\mathrm{~N}$ & 11 & 6 & 14 & 15 & 31 & 77 \\
\hline & $\begin{array}{l}\% \text { GF } \\
\% \text { total }\end{array}$ & $\begin{array}{c}12 \\
68,8\end{array}$ & $\begin{array}{r}7,8 \\
35,3\end{array}$ & $\begin{array}{l}18,2 \\
56,0\end{array}$ & $\begin{array}{l}19,5 \\
68,2\end{array}$ & $\begin{array}{l}40,3 \\
57,4\end{array}$ & $\begin{array}{c}100,0 \\
57,5\end{array}$ \\
\hline \multirow[t]{2}{*}{ M } & $\begin{array}{c}\mathrm{N} \\
\% \mathrm{GM}\end{array}$ & $\begin{array}{c}5 \\
8,8\end{array}$ & $\begin{array}{c}11 \\
19,3\end{array}$ & $\begin{array}{c}11 \\
19,3\end{array}$ & $\begin{array}{c}7 \\
12,3\end{array}$ & $\begin{array}{c}23 \\
40,4\end{array}$ & $\begin{array}{c}57 \\
100,0\end{array}$ \\
\hline & $\%$ total & 31,3 & 64,7 & 44,0 & 31,8 & 42,6 & 42,5 \\
\hline
\end{tabular}

Dos alvos de bullying tem-se $68,8 \%$ das meninas que não foram vitimadas e das que sofreram bullying $23,4 \%$ sofreu uma ou duas vezes, nos meninos $(71,7 \%)$ não foi vítima de e $23,3 \%$ sofreu uma ou duas vezes. Ao comparar os grupos $50 \%(\mathrm{~N}=2)$ dos meninos sofreram bullying mais de uma vez por semana e as meninas $(66,7 \%)$ sofreram de três a seis vezes por semana. (Tabela II) 
Tabela II - Frequência e Percentual da quantidade de vezes que sofreu bullying nas aulas de Educação Fisica por sexo.

\begin{tabular}{llllllll}
\hline Sexo & & NSB & 1 ou $\mathbf{2 x}$ & $\mathbf{3}$ a $\mathbf{6 x}$ & $\mathbf{1 x / s e m}$ & $\mathbf{+ 1 x / s e m}$ & Total \\
\hline \multirow{3}{*}{$\mathbf{F}$} & $\mathbf{N}$ & 53 & 18 & 2 & 2 & 2 & 77 \\
& $\%$ GF & 68,8 & 23,4 & 2,6 & 2,6 & 2,6 & 100,0 \\
& $\%$ total & 55,2 & 56,3 & 66,7 & 100,0 & 50,0 & 56,2 \\
\cline { 2 - 7 } & N & 43 & 14 & 1 & 0 & 2 & 60 \\
M & $\%$ GM & 71,7 & 23,3 & 1,7 & 0 & 3,3 & 100,0 \\
& $\%$ total & 44,8 & 43,8 & 33,3 & 0 & 50,0 & 43,8 \\
\hline
\end{tabular}

F-Feminino; M - Masculino; NSB - Não sofri bullying nas aulas de Educação Física; 1 ou 2x Só uma ou duas vezes; 3 a $6 \mathrm{x}$ - De três a seis vezes; $1 \mathrm{x} / \mathrm{sem}$ - Uma vez por semana; +1x/sem Várias vezes por semana; \%GF - Grupo Feminino; \%GM - Grupo Masculino.

Quanto ao tipo de bullying mais usado contra as meninas $(58,3 \%)$ e os meninos $(55,6 \%)$ foi encontrado o tipo verbal por meio da alternativa que apresentava as palavras: "coloquei apelido, xinguei ou ri deles". Ao comparar os grupos observa-se que 77,8\% das meninas tendem sofrer o bullying psicológico/moral, o qual foi identificado a partir das palavras: "ameacei" e "não deixei eles conversarem, ficarem juntos ou brincarem com outros colegas", assim como os meninos $(75,0 \%)$. Logo, o tipo psicológico/moral e mais encontrado tanto nas meninas como nos meninos vítimas. (Tabela III)

Tabela III - Frequência e Percentual do tipo de bullying mais usado contra a vitima por sexo.

\begin{tabular}{lllllllll}
\hline Sexo & & ECB & A & AXR & N/CFJB & MFG & OC & Total \\
\hline \multirow{3}{*}{ F } & N & 1 & 1 & 14 & 0 & 7 & 1 & 24 \\
& $\%$ GF & 4,2 & 4,2 & 58,3 & 0 & 29,2 & 4,2 & 100,0 \\
& $\%$ total & 33,3 & 25,0 & 58,3 & 0 & 77,8 & 100,0 & 57,1 \\
\cline { 2 - 9 } & N & 2 & 3 & 10 & 1 & 2 & 0 & 18 \\
\multirow{3}{*}{ M } & $\%$ GM & 11,1 & 16,7 & 55,6 & 5,6 & 11,1 & 0 & 100,0 \\
& $\%$ total & 66,7 & 75,0 & 41,7 & 100,0 & 22,2 & 0 & 42,9 \\
\hline
\end{tabular}

F - Feminino; M - Masculino; ECB - Me empurram, chutam, batem; A - Me ameaçam; AXR Me colocam apelidos, me xingam ou riem de mim; N/CFJB - Não me deixam conversar, ficar junto ou brincar com outros colegas; MFG - Contam mentiras ou fazem fofocas a meu respeito e tentam fazer com que os outros não gostem de mim; OC - Outras coisas; \%GF - Grupo Feminino; \%GM - Grupo Masculino.

Sobre o sexo dos agressores, na Tabela IV, as meninas afirmam ser agredidas tanto por meninos como por meninas $(39,1 \%)$ e os meninos $(55,6 \%)$ somente por meninos. Ao comparar os grupos as meninas 
tendem a ser agredidas principalmente por meninos $(66,7 \%)$ e os meninos $(55,6 \%)$ somente por meninos. Dessa maneira, o sexo do agressor tende a ser o mesmo da vítima.

Tabela IV - Frequência e Percentual do sexo dos agressores.

\begin{tabular}{llllllll}
\hline Sexo & & $\mathbf{S M}^{\text {nos }}$ & $\mathbf{P M}^{\text {nos }}$ & $\mathbf{M}^{\text {nas }}$ & $\mathbf{P M}^{\text {nas }}$ & $\mathbf{M}^{\text {nos }} / \mathbf{M}^{\text {nas }}$ & Total \\
\hline \multirow{3}{*}{$\mathbf{F}$} & $\mathbf{N}$ & 7 & 2 & 3 & 2 & 9 & 23 \\
& $\%$ GF & 30,4 & 8,7 & 13,0 & 8,7 & 39,1 & 100,0 \\
& $\%$ total & 41,2 & 66,7 & 75,0 & 100,0 & 60,0 & 56,1 \\
\cline { 2 - 7 } $\mathbf{M}$ & $\mathbf{N}$ & 10 & 1 & 1 & 0 & 6 & 18 \\
& $\%$ GM & 55,6 & 5,6 & 5,6 & 0 & 33,3 & 100,0 \\
& $\%$ total & 58,8 & 33,3 & 25,0 & 0 & 40,0 & 43,9 \\
\hline
\end{tabular}

F - Feminino; M - Masculino; SM ${ }^{\circ 0 s}$ - Só por meninos; PM $^{\text {nos }}$ - Principalmente por meninos; $M^{n 35}$ - Só por meninas; $\mathrm{PM}^{\mathrm{n35}}$ - Principalmente por meninas; $\mathrm{M}^{\mathrm{nos}} / \mathrm{M}^{\mathrm{n} 35}$ Tanto por meninos quanto por meninas; \%GF - Grupo Feminino; \%GM - Grupo Masculino.

Quanto ao porque das ações dos agressores, Tabela V, 35,9\% das meninas acreditam que o bullying ocorre porque os agressores são mais fortes e os meninos empatam com 30,8\% em ter como motivo a brincadeira e superioridade de força do agressor.

Tabela V - Frequência e Percentual das prováveis justificativas para as ações dos agressores.

\begin{tabular}{|c|c|c|c|c|c|c|c|c|c|}
\hline \multicolumn{2}{|c|}{ Sexo } & \multirow{2}{*}{$\begin{array}{l}\text { NS } \\
16\end{array}$} & \multirow{2}{*}{\begin{tabular}{|l|} 
PB \\
22
\end{tabular}} & \multirow{2}{*}{$\begin{array}{l}\text { PSMF } \\
28\end{array}$} & \multirow{2}{*}{$\begin{array}{l}\text { PSP } \\
0\end{array}$} & \multirow{2}{*}{$\begin{array}{l}\text { PVDO } \\
7\end{array}$} & \multirow{2}{*}{$\begin{array}{l}\text { PVMC } \\
0\end{array}$} & \multirow{2}{*}{$\begin{array}{l}\text { OR } \\
5\end{array}$} & \multirow{2}{*}{$\begin{array}{l}\text { Total } \\
78\end{array}$} \\
\hline & $\mathrm{N}$ & & & & & & & & \\
\hline \multirow[t]{3}{*}{$\mathbf{F}$} & $\%$ GF & 20,5 & 28,2 & 35,9 & 0 & 9,0 & 0 & 6,4 & 100,0 \\
\hline & $\%$ total & 51,6 & 57,9 & 63,6 & 0 & 70,0 & 0 & 100,0 & 60,0 \\
\hline & $\mathrm{N}$ & 15 & 16 & 16 & 1 & 3 & 1 & 0 & 52 \\
\hline \multirow[t]{2}{*}{ M } & $\% \mathrm{GM}$ & 28,8 & 30,8 & 30,8 & 1,9 & 5,8 & 1,9 & 0 & 100,0 \\
\hline & $\%$ total & 48,4 & 42,1 & 36,4 & 100,0 & 30,0 & 100,0 & 0 & 40,0 \\
\hline
\end{tabular}

A Tabela VI, referente a ação das testemunhas de bullying, as meninas que viram alguém sofrendo bullying pediram ajuda a algum funcionário da escola, direção ou professor $(19,0 \%)$ e dos meninos que presenciaram bullying pediram aos agressores para pararem $(20,7 \%)$. Assim, a as meninas procuram ajudar a vítima de forma in- 
direta, procurando algum adulto e os meninos de forma mais explicita, pedindo diretamente ao agressor para parar.

Tabela VI - Frequência e Percentual da atitude tomada diante de situações de bullying por sexo.

\begin{tabular}{llllllll}
\hline Sexo & & NVNSBEF & EDAP & PADPF & ESCSB & NFN & Total \\
\hline \multirow{2}{*}{ F } & N & 43 & 10 & 15 & 4 & 7 & 79 \\
& $\%$ GF & 54,4 & 12,7 & 19,0 & 5,1 & 8,9 & 100,0 \\
& $\%$ total & 58,1 & 45,5 & 78,9 & 50,0 & 50,0 & 57,7 \\
\cline { 2 - 7 } M & N & 31 & 12 & 4 & 4 & 7 & 58 \\
& $\%$ GM & 53,4 & 20,7 & 6,9 & 6,9 & 12,1 & 100,0 \\
& $\%$ total & 41,9 & 54,5 & 21,1 & 50,0 & 50,0 & 42,3 \\
\hline
\end{tabular}

F - Feminino; M - Masculino; NVNSBEF - Nunca vi ninguém sofrendo bullying nas aulas de educação física; EDAP - Eu disse aos agressores que parassem; PADPF Pedi ajuda a direção, professor ou funcionário da escola; ESCSB - Eu socorri o colega que estava sofrendo bullying; NFN - Não fiz nada; \%GF - Grupo Feminino; \%GM Grupo Masculino.

A Tabela VII mostra, que o tipo de bullying mais frequente entre as agressoras $(66,7 \%)$ é o verbal e nos meninos o verbal $(40,0 \%)$ e o psicológico/moral $(35,0 \%)$. Ao comparar os grupos, as meninas $(66,7 \%)$ e os meninos $(70,0 \%)$ realizam mais o psicológico/moral, não sendo encontrado o tipo de bullying físico/material entre as meninas. Sendo utilizado para identificação do tipo físico/material a alternativa: "bati, dei pontapés, empurrei" e "quebrei ou peguei as coisas e o dinheiro deles"; para o tipo verbal a alternativa: "coloquei apelido, xinguei ou ri deles"; e o psicológico/moral: "ameacei" e "não deixei eles conversarem, ficarem juntos ou brincarem com outros colegas".

Tabela VII - Frequência e Percentual do tipo de bullying utilizado contra outros colegas nas aulas de Educação Física por sexo.

\begin{tabular}{llllllll}
\hline Sexo & & BPE & A & QPCDD & CAXRD & NDECFJBCOC & Total \\
\hline \multirow{3}{*}{ F } & N & 0 & 2 & 1 & 12 & 3 & 18 \\
& $\%$ GF & 0 & 11,1 & 5,6 & 66,7 & 16,7 & 100,0 \\
& $\%$ total & 0 & 66,7 & 50,0 & 60,0 & 30,0 & 47,4 \\
\cline { 2 - 7 } & N & 3 & 1 & 1 & 8 & 7 & 20 \\
M & $\%$ GM & 15,0 & 5,0 & 5,0 & 40,0 & 35,0 & 100,0 \\
& $\%$ total & 100,0 & 33,3 & 50,0 & 40,0 & 70,0 & 52,6 \\
\hline
\end{tabular}

F - Feminino; M - Masculino; BPE - Bati, dei pontapés, empurrei; A - Ameacei; QPCDD - Quebrei ou peguei as coisas e o dinheiro deles; CAXRD - Coloquei apelido, xinguei ou ri deles; NDECFJBCOC - Não deixei eles conversarem, ficarem juntos ou brincarem com outros colegas; \%GF - Grupo Feminino; \%GM - Grupo Masculino. 
Sobre o sentimento do agressor, Tabela VIII, as meninas $(35,3 \%)$ acham a agressão engraçada e os meninos empatam em $25,0 \%$ em acharem engraçado e se sentirem mal. Ao comparar os grupos, as meninas $(80,0 \%)$ tendem a não sentirem nada em relação a vítima e os meninos $(75,0 \%)$ sentem pena da vítima.

Tabela VIII - Frequência e Percentual do sentimento dos agressores ao

fazerem bullying contra outros colegas durante as aulas de Educação Física

por sexo.

\begin{tabular}{|c|c|c|c|c|c|c|c|c|c|c|}
\hline Sexo & & EMSB & FE & SEMC & NSN & EMSM & ESPC & AEFMC & $\begin{array}{l}\text { EPPF } \\
\text { PD }\end{array}$ & Total \\
\hline \multirow{3}{*}{$\mathbf{F}$} & $\mathrm{N}$ & 0 & 6 & 1 & 4 & 4 & 1 & 1 & 0 & 17 \\
\hline & $\%$ GF & 0 & 35,3 & 5,9 & 23,5 & 23,5 & 5,9 & 5,9 & 0 & 100,0 \\
\hline & $\%$ total & 0 & 54,5 & 33,3 & 80,0 & 44,4 & 25,0 & 33,3 & 0 & 45,9 \\
\hline \multirow{3}{*}{ M } & $\mathrm{N}$ & 1 & 5 & 2 & 1 & 5 & 3 & 2 & 1 & 20 \\
\hline & $\% \mathrm{GM}$ & 5,0 & 25,0 & 10,0 & 5,0 & 25,0 & 15,0 & 10,0 & 5,0 & 100,0 \\
\hline & $\%$ total & 100,0 & 45,5 & 66,7 & 20,0 & 55,6 & 75,0 & 66,7 & 100,0 & 54,1 \\
\hline
\end{tabular}

F - Feminino; M - Masculino; EMSB - Eu me senti bem; FE - Foi engraçado; SEMC Senti que eles mereciam um castigo; NSN - Não senti nada; EMSM - Eu me senti mal; ESPC - Eu senti pena do colega; AEFMC - Acho que eles fariam o mesmo comigo; EPPFPD - Estava preocupado que algum professor, funcionário ou pais, descobrissem; \%GF - Grupo Feminino; \%GM - Grupo Masculino.

\section{Discussão}

O questionário de bullying utilizado aborda o fenômeno dentro da instituição escolar, podendo ter suas perguntas direcionadas para as aulas de Educação Física. Antes da aplicação do questionário, em cada turma foi perguntado se eles conheciam o que era bullying, todos os indivíduos se mostraram cientes do assunto pesquisado até expondo sua própria definição acerca da temática. Dessa forma evitou-se o resultado de Levandoski e Cardoso (2010) que mostrou que todas as meninas $(100 \%)$ e a maioria dos meninos $(96,7 \%)$ não conheciam o fenômeno. $\mathrm{O}$ presente trabalho não apresentou diferença significativa dentro de seus grupos devido às várias divisões de grupos e o baixo quantitativo de indivíduos na amostra.

No presente estudo, tanto nas meninas como nos meninos, vítimas e agressores, foi encontrado o tipo de bullying psicológico/moral. O tipo de bullying físico/material não foi encontrado no grupo feminino, o que não ocorreu no masculino. Encontraram-se mais meninas vítimas e testemunhas e meninos agressores e vitimas/agressoras. Com relação ao fazer o bullying junto com outros indivíduos, as meninas se destacaram afirmando que geralmente obtiveram a ajuda de mais de 
oito pessoas para realizar a agressão enquanto os meninos afirmam fazer sozinhos.

O trabalho de Oliveira (2007) mostrou que $62 \%, 59 \%$ e $81 \%$ dos alunos do ensino médio das três escolas pesquisadas se encaixaram no perfil de vítimas, discordando deste estudo que mostra que a maioria $(19,9 \%)$ se encaixou no perfil de vitimas/agressoras. O estudo de Sabino (2010) nas aulas de Educação Física teve 46\% dos indivíduos considerados como vítimas. Porém, esses dados não separam os indivíduos pelo sexo.

Bandeira (2009) mostrou que o bullying mais encontrado nas vítimas foi o verbal $(61,1 \%)$ seguido do psicológico/moral $(25,7 \%)$; dentre estes o mais comum nos meninos foi o bullying físico e entre as meninas, o psicológico. Já o bullying mais usado pelos agressores foi o verbal $(70,7 \%)$ e o físico $(15,4 \%)$; nos meninos, houve a prevalência do tipo físico e nas meninas, o psicológico. Neste mesmo estudo a autora encontrou a predominância de meninas como vítimas $(25,9 \%)$ e testemunhas $(17,3 \%)$ e dos meninos como agressores $(18,0 \%)$ e vítimas/agressoras $(42,2 \%)$ corroborando com os perfis identificados neste estudo.

Oliboni e Lunardi (2011) ressaltam que o tipo de bullying mais comum entre os meninos foi o físico e o verbal; já entre as meninas, $\mathrm{o}$ mais comum foi o verbal e psicológico; também foi mais comum entre elas a capacidade de persuasão de outras meninas para a agressão, não sendo essa diferença significativa entre os sexos.

Francisco e Libório (2009) afirmaram que, em seu estudo, o tipo de bullying mais encontrado na $5^{\circ}$ série do ensino fundamental foi o físico com $23,30 \%$ consideradas vítimas e $41,50 \%$ nunca terem presenciado o bullying na escola. Ressaltando que o momento mais comum para sua ocorrência é o intervalo.

O trabalho de Freire, Simão e Ferreira (2006) mostra que meninas tendem a estar relacionadas ao bullying verbal e psicológico, enquanto os meninos no tipo físico, ambos como vítimas e agressores. De acordo com essas autoras, há uma predominância dos meninos dentro do perfil de agressores e das meninas, dentro do perfil de vítimas. Isso acontece, pois da mesma forma que os modelos de gênero e seus papéis mudam de acordo com o tempo, os tipos de agressões também podem se modificar, o que justifica a diferença dos dados desse estudo para os demais, $7 \%$ dos indivíduos dessa pesquisa presenciaram o bullying. 
Segundo Oliveira e Votre (2006) as meninas eram vitimadas por participarem pouco ou não participarem das aulas de Educação Física e os meninos por possuírem pouca habilidade motora, atitudes que são reflexos dos padrões impostos para cada sexo, sendo que meninas "não devem" participar de atividade violentas, demonstrando fragilidade e sensibilidade e meninos "devem" ser violentos.

No resultado encontrado nesta pesquisa o sexo da vítima tende a ser o mesmo do agressor. Bandeira (2009) discorda com os achados desse estudo quando mostra que as meninas $(20,9 \%)$ sofrem bullying de outras meninas e corrobora ao afirmar que os meninos (36,7\%) sofrem mais bullying de outros meninos.

A maioria dos indivíduos, meninas e meninos, declararam nunca terem sofrido bullying nas aulas de Educação Física. Dos que sofreram, houve destaque para as meninas $(23,4 \%)$ vitimadas uma ou duas vezes e para os meninos $(23,3 \%)$, que também foram vitimados uma ou duas vezes. Sabino (2010) mostra que $46 \%$ não presenciaram o bullying nas aulas de Educação Física, mas 57\% afirmam acontecer sempre ou casualmente. No estudo de Bandeira (2009), a maioria dos indivíduos $(67,5 \%)$ sofreram bullying e assim como o presente estudo, não houve diferença significativa entre o sexo das vítimas: meninos $(27,3 \%)$ e meninas $(33,6 \%)$ sofreram bullying uma ou duas vezes por semana.

No estudo de Almeida, Cardoso e Costac (2009), os docentes estudados associaram as práticas preconceituosas a fatores econômicos, familiares e raciais, ressaltando que os acontecimentos dessas situações não dependem do gênero.

Em pesquisa realizada por Sabino (2010), os educadores concluíram ser mais comum nas aulas de Educação Física a rejeição de alunos motoramente menos habilidosos e a liderança de indivíduos fisicamente mais fortes que os demais. O professor entrevistado afirmou utilizar como estratégia os jogos cooperativos para promover a socialização e participação de todos, evitando a aplicação de jogos competitivos, nos quais a vontade de vencer facilitará a segregação de alunos com habilidades motoras diferentes. Como principal meio de intervenção nos 3 principais tipo de agressão, físico/material, verbal psicológico/moral, os professores procuram, através do diálogo, compreender o ocorrido e encaminhar o caso para a direção escolar; os professores alertam para a necessidade da conscientização de todos os 
funcionários da escola e de todos os familiares sobre os casos de bullying.

Na Educação Física Escolar uma forma de combater comportamentos agressivos dentro das aulas de Educação Física é a utilização de músicas, jogos, interdisciplinaridade, dinâmicas, esportes e eventos, desde que estes temas sejam abordados de maneira organizada e contextualizada, pois assim as aulas contribuirão para o desenvolvimento do indivíduo como cidadão e cidadã (FERNANDES; SOUZA, 2008).

A maioria das situações de violência escolar estão com a sua solução dentro da própria instituição de ensino, a observação é a principal forma de reconhecimento de casos de bullying. Para prevenção, é indispensável o trabalho conjunto de pais, alunos, professores e demais funcionários da escola, para que, através da conscientização de todos e suporte às vítimas, haja a diminuição da violência escolar. É extremamente importante conquistar a confiança da vítima para que assim ela fale sobre seus agressores e as agressões físicas ou verbais cometidas sobre ela. Quanto aos agressores, evitar punições que possam contribuir para um maior desenvolvimento de sua agressividade, buscando colocá-los a par das consequências de seus atos, para ele mesmo e para o outro, não o vendo como um "vilão", mas sim como alguém que também sofre e necessita de ajuda. Com relação aos projetos antibullying, este mesmo autor alerta para ser levada em consideração a especificidade de cada escola, não podendo considerá-la como algo homogêneo (LOPES NETO, 2005). Para as escolas, existe o projeto "Educar para a paz", desenvolvido por Fante (2005), em que procura intervir na identificação dos envolvidos e com toda a instituição escolar e os próprios alunos, buscando minimizar as consequências e aumentar a conscientização sobre este fenômeno.

Os meninos que colocaram relatos sobre a alternativa: "outras coisas", escreveram de forma ilegível ou marcaram a alternativa e não colocaram sua opinião. As vítimas que relataram terem sofrido outro tipo de agressão afirmaram o seguinte: "eles ficaram falando mal da minha família e me colocavam apelidos." (aluna do $6^{\circ}$ ano). Quanto à reação ao bullying sofrido, a mesma aluna concluiu: "eles me xingaram e eu xinguei eles também." Outra vítima do sexo feminino relata que: "me chamam de gordona na aula de Educação Física, falam que eu não aguentava correr." Sobre a atitude diante do bullying: "parei de fazer as aulas de Educação Física." Sobre o que acham dos agressores 
encontra-se: "eles são debochados;" "muitos valentões gostam de se mostrar;" "porque são covardes e maiores que a vítima;" "pois eles são diferentes ou inteligentes demais, ou porque ele tem a pele de cor diferente;" "porque eles querem aparecer". Neste segundo caso, é possível perceber um caso de evasão das aulas devido ao bullying e sua origem sempre a partir de características relacionadas ao aspecto motor e físico. Exemplos semelhantes foram encontrados por Fante (2005) que apresenta alguns relatos de situações de bullying nas aulas de Educação Física.

Ao observar o bullying dentro da Educação Física, o fato de meninos serem menos habilidosos ou não se interessarem por atividades consideradas adequadas para o sexo faz com que sofram com apelidos. Vale ressaltar que o bullying pode ter seu início nas aulas de Educação Física e sua continuidade, fora dela, fazendo com que a Educação Física haja como promotora do fenômeno. No exemplo seguinte fornecido por Fante (2005), é possível observar um caso em que a aluna sofre bullying duplo: além dos colegas, também o professor participa desta humilhação.

Pupo (2007) aponta que os meninos (56\%) foram maioria em comparação às meninas (44\%) ao apresentarem sentimentos pessoais negativos, como baixa autoestima. Mais meninas (53\%) tiveram sentimentos provocados pelos prejuízos concretos, quando comparadas aos meninos (47\%). Também as meninas $(60 \%)$, quando comparadas aos meninos (40\%), tiveram seus sentimentos relacionados à injustiça e por fim, mais meninos (58\%) apresentaram seus sentimentos referentes à ação (meninas $=42 \%$ ). A autora atenta para esse resultado estar diretamente ligado a questões de gênero, em que a sociedade exige dos meninos um comportamento em frente a situações de violência, não aceitando sua condição inferior diante do outro. Deve-se levar em consideração a idade da população: que entre os 15 e 17 anos se encontram com a sua autoestima mais ligada aos outros.

É necessário que os pais observem o comportamento de seus filhos, refletindo sobre como está sendo os modelos familiares apresentados, importante também é destacar as qualidades e potencialidades não estimulando uma reação diante da agressão sofrida, sempre com o cuidado para não tomarem partido antecipado sobre o perfil de seu filho ou filha diante do bullying (FANTE, 2005). 


\title{
Conclusões
}

Pode-se concluir que não houve diferença significativa entre o gênero masculino e feminino com os tipos de bullying mais frequentes nas aulas de Educação Física Escolar, uma vez que este estudo mostra que tanto meninos como meninas sofreram o bullying psicológico/moral independente de serem vítimas ou agressores, entretanto, houve mais meninos agressores do que meninas.

No que se refere às meninas o tipo psicológico/moral é realmente mais comum, como visto na discussão, pois não se espera delas, comportamentos explícitos e explosivos a ponto de chamar a atenção de todos, como ocorreria em uma agressão física, que é mais difícil de camuflar. Outro fator observado é que meninas tendem a persuadir mais outras pessoas para realizar o bullying quando comparadas com os meninos, realçando a necessidade de complacência.

Já quanto aos meninos, o tipo de bullying mais frequente dentro da literatura é o físico, porém este trabalho aponta que o mais encontrado, no perfil de vítima e agressor é o tipo psicológico/ moral, sendo igual ao resultado do grupo feminino. Como apresentado na revisão e na discussão desta pesquisa, observa-se que os fatores que influenciam o conceito de gênero se modificam de acordo com o tempo e com a cultura. Assim, vê-se que, para esta população, o tipo de comportamento imposto para os meninos não mais estão voltados para as valências físicas, porém, eles continuam agindo de acordo com a sua função de protetores defendo a si e ao outro. $\mathrm{O}$ que mudou foi a forma como essa função de proteção se apresentou, deixando de ser por meio de conflitos físicos.

Assim, percebe-se uma mudança, dentro do gênero masculino quando referente ao tipo de reação diante de um conflito, o que não deixa de se refletir nos comportamentos impostos para os meninos, e na população feminina. Os comportamentos apresentados neste trabalho corroboram os demais achados, pois os tipos de comportamentos e os tipos de violências foram condizentes.

\section{Bullying in school physical education and differences between boys and girls}

\begin{abstract}
The aim of this study was to analyse the relationship of gender with the most common types of bullying in school physical education classes of the 6th year of primary education schools. We selected the four largest schools in the Itaperuna City
\end{abstract}


and applied a questionnaire of bullying in 141 students. The differences between the sexes were not significant and is most commonly found in girls who are victims of verbal bullying type and "psychological/moral" and the "verbal" victims in boys and "psychological/moral". By comparing the result of girls and boys is observed the prevalence of psychological type/moral for both. It can be conclude that the most common type of bullying in physical education classes, was among the "psychological/moral", was not found differences between boys and girls or between victims and aggressors.

Keywords: Bullying. Gender Identity. Physical Education and Training.

\section{Bullying en la educación física escolar y sus diferenciais entre niños y niñas}

\section{Resumen}

El objetivo fue analizar la relación del género con los tipos de bullying más frecuentes en las aulas de Educación Física Escolar del $6^{\circ}$ año de la Enseñanza Fundamental. Fueron seleccionadas las cuatro mayores escuelas de la red municipal de Itaperuna y aplicado un questionário sobre bullying en 141 estudiantes. Se verificó que las diferencias entre los sexos no fueron significativas, siendo más encontrado en las niñas víctimas de bullying el tipo verbal y el psicológico/moral y en los niños víctimas el verbal y psicológico/moral. El bullying más común entre los grupos fue el psicológico/moral, no presentando diferencia entre niños y niñas, ni entre víctimas y agresores. No hube cambio en el comportamiento femenino; en los niños hube cambio en la forma de agresión o reacción.

Palabras clave: Acoso Escolar. Identidad de Género. Educación y Entrenamiento Físico.

\section{Referências}

ALMEIDA, S. B.; CARDOSO; L. R. D.; COSTAC, V. V. Bullying: Conhecimento e prática pedagógica no ambiente escolar. Psicologia Argumento, Curitiba, v. 27, n. 58, p. 201-206, jun./set., 2009.

BANDEIRA, C. M. Bullying: auto-estima e diferenças de gênero. 2009. 69 f. Dissertação (Mestrado em Psicologia do Desenvolvimento)-Curso de em Psicologia do Desenvolvimento, Instituto de Psicologia, Universidade Federal do Rio Grande do Sul, Porto Alegre, 2009.

FANTE, C. Fenômeno Bullying: como prevenir a violência nas escolas e educar para a paz. Campinas: Versus, 2005.

FANTE, C.; PEDRA, J. A. Bullying Escolar: perguntas e respostas. Porto Alegre: Artmed, 2008. 
FERNANDES, C. D. A.; SOUZA, M. F. Na escola: como lidar com comportamentos agressivos? Portal Prómenino, 09 maio 2008. Disponível em <http://www.promenino.org.br/Default.aspx?TabId=77\&ConteudoId=496e4d57-99b3-4f54-8b17-9f9ce14a2b3e > Acesso em: 4 jul. 2011.

FRANCISCO, M. V.; LIBÓRIO, R. M. C. Um Estudo sobre Bullying entre Escolares do Ensino Fundamental. Psicologia: Reflexão e Crítica, Porto Alegre, v. 22, n. 2, p. 200-207, 2009.

FREIRE, I. P.; SIMÃO, A. M. V.; FERREIRA, A. S. O estudo da violência entre pares no $3^{\circ}$ ciclo do ensino básico: um questionário aferido para a população escolar portuguesa. Revista Portuguesa de Educação, Barga, v. 19, n. 2, p. 157-183, 2006.

KNIJINIK, J. D. Gênero e esporte: masculinidades e feminilidades. Rio de Janeiro: Apicuri, 2010.

LEVANDOSKI, G.; CARDOSO, F.L. Percepção docente sobre as relações de agressividade, o lúdico e o bullying na escola. Pensar a Prática, Goiânia, v. 13, n. 2, p. 1-13, maio/ago., 2010.

LOPES NETO, A. A. Bullying: comportamento agressivo entre estudantes. Jornal de Pediatria, Rio de Janeiro, v. 81, n. 5, p. 164-172, set./out., 2005.

LOURO, G. L. Gênero, sexualidade e educação. Uma perspectiva pós-estruturalista. Petrópolis, Rio de Janeiro: Vozes, 2003.

OLIBANI, S.P.; LUNARDI, V. L. O bullying nas diferenças entre meninos e meninas. In: SEMINÁRIO DE CORPO, GÊNERO E SEXUALIDADE: INSTANCIAS DE PRODUÇÃO NAS POLÍTICAS DA PRÓPRIA VIDA, 5., 2011, Rio Grande; SEMINÁRIO INTERNACIONAL CORPO, GÊNERO E SEXUALIDADE, 1., 2011, Rio Grande; ENCONTRO GÊNERO E DIVERSIDADE NA ESCOLA, 1., 2011, Rio Grande. Anais... Rio Grande: Universidade Federal do Rio Grande e Universidade Federal do Rio Grande do Sul, 2011. p.1251-1256

OLIVEIRA, F. F.; VOTRE, S. J. Bullying nas aulas de educação física. Movimento. Porto Alegre. v. 12, n. 2, p.173-197, maio/ago., 2006. 
OLIVEIRA, J. M. Indícios de casos de bullying no ensino médio de Araraquara - SP. 2007. 92 f. Dissertação (Mestrado em Desenvolvimento Regional e Meio Ambiente)-Centro Universitário de Araraquara (UNIARA), Araraquara, 2007. Disponível em: $<$ http://www.uniara.com.br/mestrado_drma/arquivos/dissertacao/juliana_muranetti_de_oliveira_2007.pdf $>$. Acesso em 13 maio 2011.

PUPO, K. R. Violência moral no interior da escola: um estudo exploratório das representações do fenômeno sob a perspectiva de gênero. 2007. 242 f. Dissertação (Mestrado em Psicologia da Educação)-Faculdade de Educação, Universidade de São Paulo, São Paulo, 2007. Disponível em: <http://www.teses.usp.br/teses/disponiveis/48/48134/tde-27112007-142609/pt-br.php>. Acesso em 19 ago. 2011.

SABINO, C .J. C. O fenômeno bullying na escola: pesquisando professores e alunos na Educação Física Escolar. 2010. 81 f. Monografia (Licenciatura Plena em Educação Física)-Curso de Educação/Licenciatura Plena, Centro de Ciências da Saúde, Universidade Estadual do Ceará, Fortaleza, 2010. Disponível em: $<$ http://www.bullying.pro.br/images/stories/pdf/resenhas_monografias/monografia_carla_sabino.pdf $>$. Acesso em 13 maio $2 \overline{0} 11$.

SILVA, A. B. B. Bullying: mentes perigosas na escola. Rio de Janeiro: Objetiva, 2010.

Recebido em: 29/02/2012

Revisado em: $12 / 06 / 2012$

Aprovado em: 25/09/2012

Endereço para correspondência

raquelglins@hotmail.com

Raquel Guimarães Lins

Fundação Universitária de Itaperuna.

rua Luiz Carlos Ferreira Tirado 148 - Centro Poliesportivo

Cidade Nova

28300-000 - Itaperuna, RJ - Brasil 